5 Bianchi R, Schonfeld IS, Laurent E. The dead end of current research on burnout prevalence. J Am Coll Surg 2016; 223: 424-5.

6 Weber A, Jaekel-Reinhard A. Burnout syndrome: a disease of modern societies? Occup Med 2000; 50: 512-7.

7 Bianchi R, Schonfeld IS, Vandel P, Laurent E. On the depressive nature of the "burnout syndrome": a clarification. Eur Psychiatry 2017; 41: 109-10.

doi: $10.1192 / p b .41 .6 .367$

\section{Soft diagnosis, guidelines and hard choices}

Thank you for this excellent and concise article outlining the complexities involved in neuroleptic malignant syndrome (NMS) in association with atypical antipsychotics. ${ }^{1}$ It serves as a reminder of how guidelines and diagnostic criteria can, for all their clarity, lead to vexing and imperfect choices.

This article brings to mind recent clinical cases where empiric treatment of a soft NMS diagnosis led to challenging decisions. The trouble lay in following guidelines in a patient with very clear treatment-resistant schizophrenia who had improved with clozapine. After the withdrawal of the causative agent, the duration for which antipsychotic treatment should be withheld is not completely clear. There are recognised guidelines indicating at least 5 days and monitoring for symptom resolution, whereas other guidelines say to wait 2 weeks after symptoms have settled. ${ }^{2,3}$ In addition, the atypical presentation of clozapine-associated NMS itself can lead to uncertainty and serves as a frustrating obstacle which clouds the process of decision-making. ${ }^{1}$ Moving forward, the recommendation to avoid the precipitating antipsychotic does not provide a clear answer in further management of such a patient on clozapine where other options have proved insufficient or inadequate. ${ }^{4}$

Further difficulty then may arise in persuading someone that the medication, which is associated with such an unpleasant clinical experience, is the correct choice. Particularly when recurrence of NMS on rechallenge with antipsychotics was found to be between 30 and $50 \%{ }^{4}$

In clinical practice there often is no perfect answer and rarely does the right one present itself as the easy choice. An article such as this serves to highlight the challenges present in applying uniform guidelines to complex presentations.

Karol Antczak, Registrar in Psychiatry and Elizabeth Cummings, Consultant Psychiatrist, Cluain Mhuire Mental Health Service, Dublin, Ireland; email: karol.antczak@sjog.ie

1 Sarkar S, Gupta N. Drug information update. Atypical antipsychotics and neuroleptic malignant syndrome: nuances and pragmatics of the association. BJPsych Bull 2017; 41: 211-6.

2 Semple D. Oxford Handbook of Psychiatry. Oxford University Press, 2013.

3 Taylor D, Paton C, Kapur S. The Maudsley Prescribing Guidelines in Psychiatry (Twelfth Edition). Wiley-Blackwell, 2015.

4 Bhanushali MJ, Tuite PJ. The evaluation and management of patients with neuroleptic malignant syndrome. Neurol Clin 2004; 22: 389-411.

doi: $10.1192 / p b .41 .6 .368$

\title{
Review
}

\section{Handbook of Secure Care}

Edited by Geoffrey Dickens, Philip Sugarman and Marco Picchioni

RCPsych Publications, 2015, £45 (pb) 348 pp.

ISBN: 9781909726369

The Handbook of Secure Care is a useful book for those new to the field of forensic mental health and is most relevant to those practising in England and Wales. It examines the relationship between mental disorder and offending, with individual chapters on personality disorder, intellectual disability, autism spectrum disorder and acquired brain injury. Strangely, there is little on psychosis which is the fundamental diagnosis within secure care.

The work considers the needs of specific populations such as women, young and older people, and outlines the provision of secure psychiatric services for these groups. It focuses on the basic components of secure care and includes information on risk assessment and management, and on recovery. The latter chapter is of particular use in defining the challenges we face in secure care and ways to redefine our conventional thinking. The fundamentals of psychological treatment in secure care are clearly set out and there is a helpful description of the role of nursing within that setting.
There is discussion in the first chapter on the evolution of secure and forensic mental healthcare, as well as information on the number of secure beds, but I would have welcomed an analysis of the overall estate, the needs for planning and the methods of provision. Similarly, details on pathways into or out of secure care, or on the legislation that allows us to detain people within these settings would have been valuable.

Notably, there is a good chapter by Penny \& Exworthy on human rights in secure psychiatric care - the Human Rights Act 1998 underpins much of what we do in secure care, making this especially relevant. It is followed by a chapter on quality assurance and clinical audit. It is my view that the human rights considerations and the quality improvement agenda are so crucial to our work that it would have been beneficial to place these chapters near the beginning of the book to emphasise their importance.

Lindsay Thomson, Professor of Forensic Psychiatry, University of Edinburgh, UK; email: I.d.g.thomson@ed.ac.uk

doi: 10.1192/pb.bp.115.052704

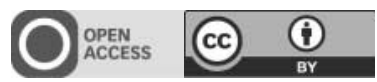

C 2017 The Author. This is an open-access article published by the Royal College of Psychiatrists and distributed under the terms of the Creative Commons Attribution License (http://creativecommons.org/licenses/by/ 4.0), which permits unrestricted use, distribution, and reproduction in any medium, provided the original work is properly cited. 